Volume 3: Task 2.3

\title{
Technical Basis for Radiological Emergency Plan Annex for WTD Emergency Response Plan: West Point Treatment Plant
}

\author{
Eva Eckert Hickey \\ Daniel J. Strom
}

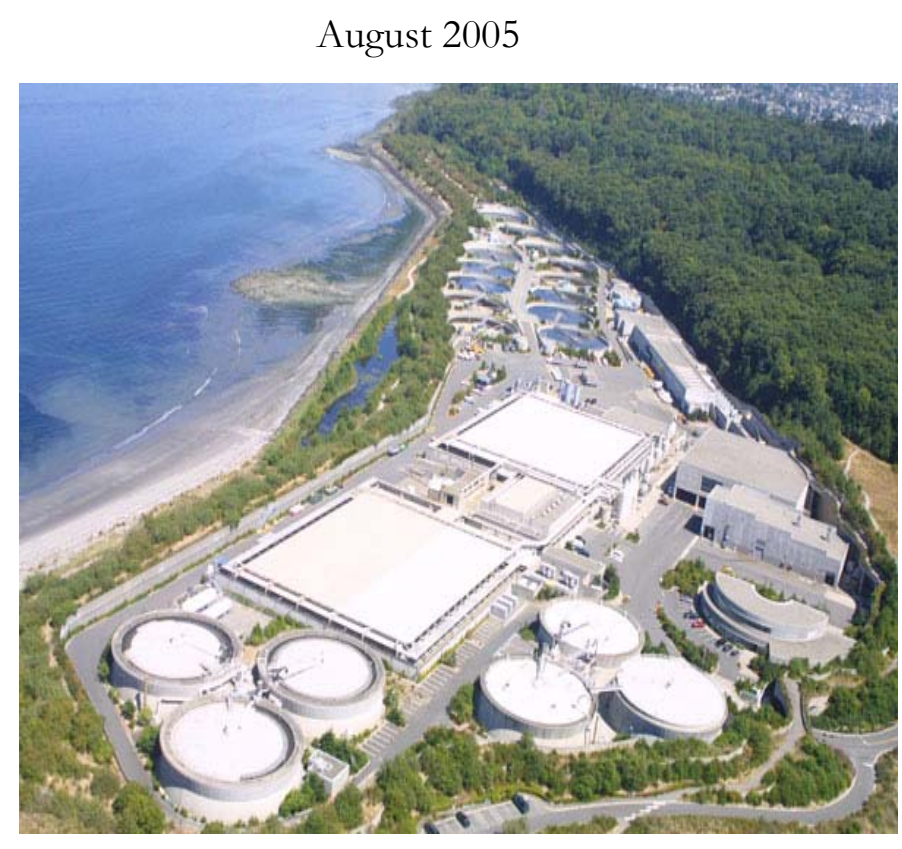

Prepared for King County, Washington, under a grant from the Department of Homeland Security as a work for others project under U.S. Department of Energy contract DE-AC05-76RL01830

Pacific Northwest National Laboratory Richland, Washington 99252 


\title{
DISCLAIMER
}

This report was prepared as an account of work sponsored by an agency of the United States Government. Neither the United States Government nor any agency thereof, nor Battelle Memorial Institute, nor any of their employees, makes any warranty, express or implied, or assumes any legal liability or responsibility for the accuracy, completeness, or usefulness of any information, apparatus, product, or process disclosed, or represents that its use would not infringe privately owned rights. Reference herein to any specific commercial product, process, or service by trade name, trademark, manufacturer, or otherwise does not necessarily constitute or imply its endorsement, recommendation, or favoring by the United States Government or any agency thereof, or Battelle Memorial Institute. The views and opinions of authors expressed herein do not necessarily state or reflect those of the United States Government or any agency thereof.

\author{
PACIFIC NORTHWEST NATIONAL LABORATORY \\ operated by \\ BATTELLE \\ for the \\ UNITED STATES DEPARTMENT OF ENERGY \\ under Contract DE-AC05-76RL01830
}

This document was printed on recycled paper.

$(9 / 2003)$ 
Volume 3: Task 2.3

\section{Technical Basis for Radiological Emergency Plan Annex for WTD Emergency Response Plan: West Point Treatment Plant}

Eva Eckert Hickey

Daniel J. Strom

August 2005

Prepared for King County, Washington, under a grant from the Department of Homeland Security as a work for others project under U.S. Department of Energy contract DE-AC05-76RL01830

Pacific Northwest National Laboratory

Richland, Washington 99352 



\section{Executive Summary}

Staff of the King County Wastewater Treatment Division (WTD) have concern about the aftermath of a radiological dispersion event (RDE) leading to the introduction of significant quantities of radioactive material into the combined sanitary and storm sewer system in King County, Washington. Radioactive material could come from the use of a radiological dispersion device (RDD). RDDs include "dirty bombs" that are not nuclear detonations but are explosives designed to spread radioactive material (National Council on Radiation Protection and Measurements (NCRP) 2001). Radioactive material also could come from deliberate introduction or dispersion of radioactive material into the environment, including waterways and water supply systems.

This document, Volume 3 of PNNL-15163 is the technical basis for the Annex to the West Point Treatment Plant (WPTP) Emergency Response Plan related to responding to a radiological emergency at the WPTP. The plan primarily considers response to radioactive material that has been introduced in the other combined sanitary and storm sewer system from a radiological dispersion device, but is applicable to any accidental or deliberate introduction of materials into the system. 



\section{Contents}

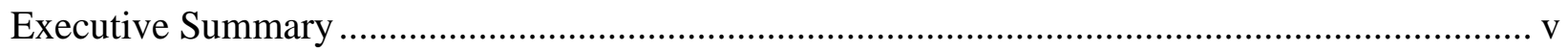

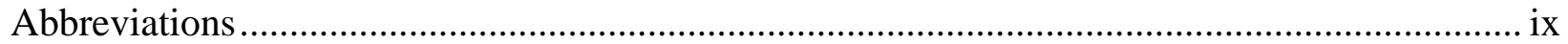

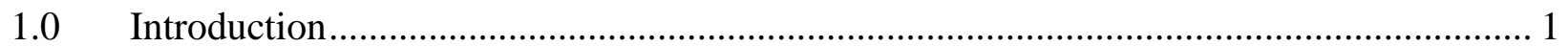

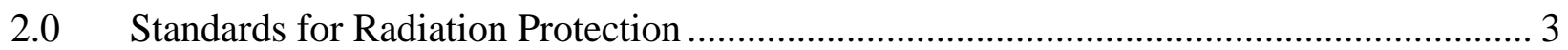

2.1 Regulations that, Amazingly Enough, Don't Apply to WTD............................................... 3

2.2 Regulations that Do Apply to WTD ………………........................................................ 3

2.2.1 Transportation ................................................................................................ 3

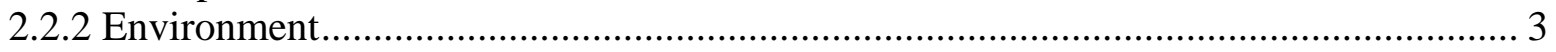

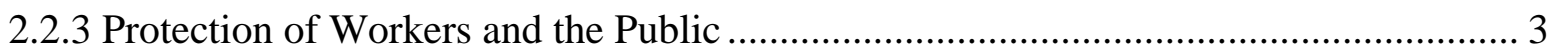

2.2.4 Disposal................................................................................................................. 5

2.3 The "As Low As Reasonably Achievable” (ALARA) Philosophy ……………..................... 6

2.4 Current Radiation Protection Recommendations.............................................................. 6

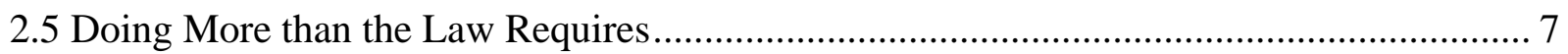

3.0 Protection of Workers During and After an Emergency ..................................................... 9

3.1 Principles of Radiation Protection and Actions Based on Those Principles ………............. 9

3.2 Protection against External Irradiation .............................................................................. 10

3.2.1 Actions Workers Can Take to Limit External Irradiation ............................................... 10

3.2.2 Actions Management Can Take to Limit External Irradiation .................................. 10

3.3 Protection against Intakes by Inhalation ……………….................................................... 11

3.3.1 Actions Workers Can Take to Limit Inhalation of Radioactive Material...................... 11

3.3.2 Actions Management Can Take to Limit Inhalation of Radioactive Material.............. 11

3.4 Protection against Intakes through Dermal Contact and by Ingestion................................. 12

3.4.1 Actions Workers Can Take to Limit Dermal Contact with, and Ingestion of,

Radioactive Material............................................................................................ 12

3.4.2 Actions Management Can Take to Limit Dermal Contact with, and Ingestion of, Radioactive Material.................................................................................................... 13

3.5 Personnel Monitoring: External Dosimetry, Bioassay, and Air Monitoring ........................ 14

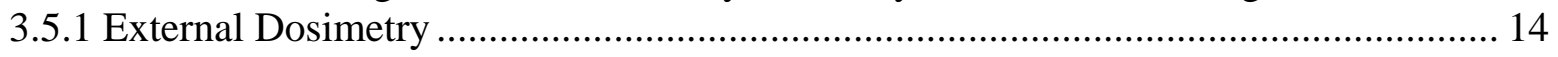

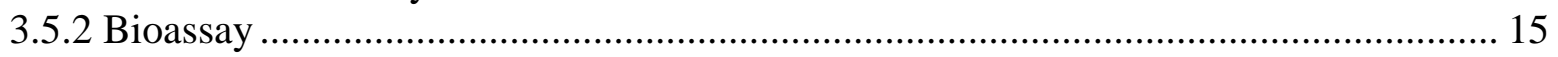

3.5.3 Air Monitoring for Personnel Dosimetry ...................................................................... 16

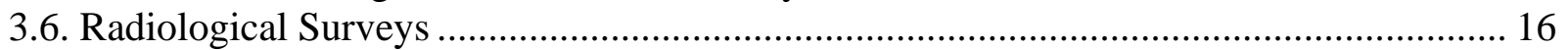

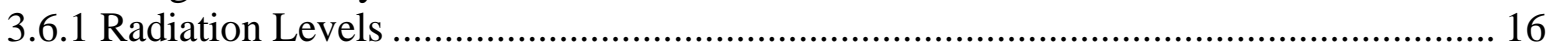

3.6.2 Surface Contamination Levels ...................................................................................... 17

3.6.3 Airborne Radioactivity Levels ..................................................................................... 17

3.6.4 Radioactive Material Concentrations in Wastewater and Other Waste Streams ......... 17

3.7 Personal Protective Equipment ........................................................................................... 18

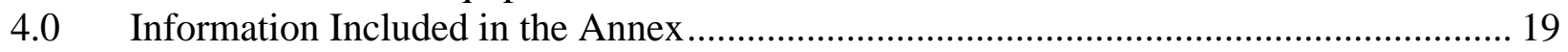

$4.1 \quad$ Purpose and Objective of the Emergency Plan............................................................. 19

$4.2 \quad$ Detecting an Event .................................................................................................. 19

4.3 Initial Response Notification and Communications during an Emergency................... 19

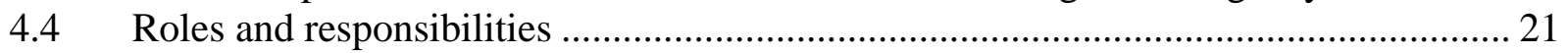

$4.5 \quad$ Protecting workers and the public............................................................................... 21

4.6 Cleanup and Decontamination ................................................................................... 21

5.0 Suggested Revisions to WPTP Emergency Plan ............................................................... 22 


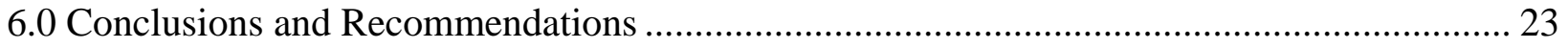

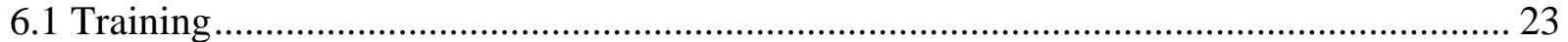

6.2 Health Physics Consulting Agreement ...................................................................... 23

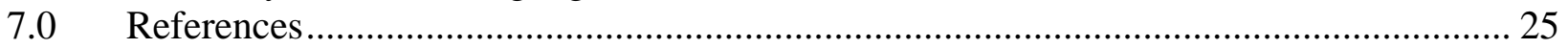

\section{Tables}

Table 1. Dose limits for external irradiation of individuals 18 years old or older in restricted areas. One-tenth of these limits apply to individuals under age 18 years................................. 4

Table 2. Limits on exposure to airborne radioactive material for individuals in restricted areas... 4

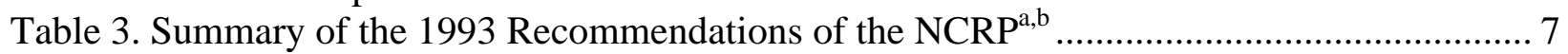

Table 4. Principles and Actions ("Commandments") of Radiation Protection ............................... 9

\section{Figures}

Figure 1. Thermo Mk. 2.3 electronic personnel dosimeter. 14

Figure 2. Photos of SIRAD dosimeters before (left) and after (right) irradiation with 100 rads of $\mathrm{x}$ rays. The color bars printed with dose numbers on each side of the sensing strip is referred to as the color reference chart. The dosimeter is the size of a thick credit card and can be carried in a wallet. 15

Figure 3. Front panel (left) and bottom (right) of Inspector. The unit has a "pancake" GeigerMuller probe built in (behind the gold screen) and can operate in count mode, count per minute mode, or dose-rate mode (in milliroentgens per hour, $\mathrm{mR} / \mathrm{hr}$ ). 17

Figure 4. Notification and Initial Response in case of a Radiological Event. 20 


\section{Abbreviations}

ALARA as low as reasonable achievable ANSI American National Standards Institute

$\mathrm{Bq}$ becquerel (1 nuclear transition per second) $\mathrm{Bq} / \mathrm{m}^{3}$ becquerels per cubic meter CdZnTe cadmium zinc telluride [detector] CERCLA Comprehensive Environmental Response, Compensation, and Liability Act Ci curie $\left(3.7 \times 10^{10}\right.$ nuclear transitions per second) cps counts per second DoD U.S. Department of Defense DOE U.S. Department of Energy DoH Washington State Department of Health DOT U.S. Department of Transportation EPA U.S. Environmental Protection Agency

FWHM full width at half maximum gal gallon

GEB Gaussian energy broadening GM Geiger-Müller [detector] HPGe high-purity germanium IND improvised nuclear device MCNP Monte Carlo N-Particle [computer code] mg milligram mrem millirem $\mathrm{NaI}(\mathrm{Tl})$ thallium-doped sodium iodide [detector]

NCRP National Council on Radiation Protection and Measurements NCRP National Council on Radiation Protection and Measurements NRC U. S. Nuclear Regulatory Commission OSHA Occupational Safety and Health Administration PNNL Pacific Northwest National Laboratory PNNL Pacific Northwest National Laboratory POTW publicly-owned treatment works PVC polyvinyl chloride RDD radiological dispersion device RDD radiological dispersion device RDE radiological dispersion event RDE radiological dispersion event RIID radioisotope identifier RPM radiation portal monitor $\mathrm{TBq}$ terabecquerel $\left(10^{12} \mathrm{~Bq} ; 1 \mathrm{Ci}=0.037 \mathrm{TBq}\right)$ UPS uninterruptible power supply VAC volts (alternating current) WAC Washington Administrative Code WPTP West Point Treatment Plant WPTP West Point Treatment Plan WTD Wastewater Treatment Division 
WTD Wastewater Treatment Division

$\mu \mathrm{Ci}$ microcurie $\left(0.000001 \mathrm{Ci}\right.$ or $\left.10^{-6} \mathrm{Ci}\right)$ 


\subsection{Introduction}

This document, Volume 3 of PNNL-15163, provides the assumptions and technical basis for the radiological Annex to the West Point Treatment Plant (WPTP) Emergency Response Plan. Suggestions to revisions or additions to the Emergency Response Plan are also provided in this report. Appendix A of the report contains the draft of the Emergency Response Plan Annex. The Annex is tied closely to the Emergency Response Plan, and does not repeat general emergency response information such as the discussion of Evacuation Procedures, Emergency Communications or the Incident Command System. Where appropriate, the Annex will refer back to the main text of the WPTP Emergency Response Plan. The Annex provides measures to be taken that will protect workers until a person trained in radiation protection can be dispatched to the plant (a consultant or an individual from the Department of Health). The assumption is that if radioactive material is detected in the wastewater, it will be processed and that workers will be trained to protect themselves using the basic radiation protection principles of limiting exposure time, maximizing distance between themselves and the source of radiation, and ensuring there is adequate shielding between themselves and the source. Personnel protective equipment (PPE) may also be used.

Responding to a radiological event is, in many ways, like responding to other hazardous material releases that may be encountered at the WPTP. However, in this case, the radioactive material will be brought into the plant from the storm and sewer systems, and not be material typically used and stored in the plant. Another major difference between other hazardous materials and radioactive material is that it cannot be detected by human senses. It cannot be smelled, tasted or seen. Therefore, in order to be aware of the materials’ presence, specialized equipment much be available to detect the material. Volume 2 of this report addresses the recommended radiological instrumentation for detection of radioactive material in the storm and sewer systems outside the WPTP and inside the plant. Until detection capability (portable monitors and dosimetry) is available in the plant, it is recommended that WPTP staff use an interim approach. This approach is to execute the bypass policy discussed in Section 5, Hazardous Material Releases of the Emergency Response Plan, once it has been verified that radioactive material is in the wastewater. This course of action is recommended to protect workers when there is no detection equipment available. Once instrumentation is available and staff have been trained in its use, then wastewater may not have to be diverted.

As discussed in Volume 1 of this report, there are two primary scenarios considered . The first scenario includes events that may be suspected from the outset, such as an explosion of a "dirty bomb" in downtown Seattle. The explosion would most likely be heard, but the type of explosion (e.g., sewer methane gas or RDD) may not be immediately known. Emergency first responders must be able to quickly detect the radioisotopes listed in previous reports, assess the situation, and respond to contain and mitigate (as much as possible) detrimental effects resulting from the incident. In such scenarios, advance notice of about an hour or two might be available before any contaminated wastewater reaches a treatment plant.

The second scenario includes events that could go initially undetected by emergency personnel. Examples of such a scenario would be the inadvertent or surreptitious introduction of radioactive material into the sewer system. Intact rogue radioactive sources from industrial radiography 
devices, well-logging apparatus, or moisture density gages may get into wastewater and be carried to a treatment plant. Other variations of this scenario include a terrorist deliberately putting a dispersible radioactive material into wastewater. Alternatively, a botched terrorism preparation of an RDD may result in radioactive material entering wastewater without anyone's knowledge. Drinking water supplies could also be contaminated, with the result that some or most of the radioactivity ends up in wastewater.

These two scenarios are considered here for developing emergency response procedures to be implemented by the WTD staff.

The Annex is designed to provide guidance and procedures to protect the staff at the WPTP. It will not discuss how to segregate, store and dispose of radioactive waste generated by contaminated wastewater. These issues are extremely important and do need to be addressed, however, they are outside the scope of the Annex.

Rather than providing detailed specific procedures for safely dealing with and handling the radioactive material in the wastewater, the Annex will provide guidance that is the same level of detail as that in the WPTP Emergency Response Plan. To be able to effectively and safely implement the Annex, training of all emergency responders will be necessary.

Should contaminated wastewater pass through the plant, it is likely that some contamination will remain on equipment and in solid effluents. Contamination remaining in the plant may or may not be a long term problem. Dealing with such situations is beyond the scope of this report.

To develop the Annex for the WPTP Emergency Response Plan, Pacific Northwest National Laboratory (PNNL) staff reviewed the June 2004 review copy of the WPTP Emergency Response Plan and toured the WPTP facility. It should be noted that the Annex is designed only to protect the workers at the WPTP and not other WTP workers outside of the facility.

Section 2 of this report contains discussions of the WTD radiation protection standards applicable to the WPTP workers. Section 3 describes the basis for protecting workers from the effects of radiation, providing guidance on what workers can do to protect themselves and what managers can do to assist staff in radiation protection. Section 4 provides an overview of the information provided in the Annex to the WPTP Emergency Response Plan. Section 5 provides suggested revisions to the Emergency Response Plan. Section 6 addresses conclusions and recommendations and Section 7 provides references. 


\subsection{Standards for Radiation Protection}

Radiation protection standards and regulations are implemented by a variety of agencies in the US, and cover dose limits for workers and members of the public, and limits on amounts and concentrations of radioactive materials that can be released to the environment. With the exception of the Comprehensive Environmental Response, Compensation, and Liability Act (CERCLA, or "Superfund"), all laws and regulations pertain to licensees or otherwise authorized parties, who have a duty to limit radiation exposures to workers, public, and the environment. Under CERCLA, sometimes a potentially responsible party cannot be identified, and the federal government accepts responsibility. For criminal acts, acts of terrorism, acts of war, and accidents of transnational consequence such as the reactor accident at Chernobyl, there may not be a potentially responsible party to whom existing regulations apply.

\subsection{Regulations that, Amazingly Enough, Don't Apply to WTD}

The Washington State Department of Health (DoH), Division of Radiation Protection has "Rules and Regulations for Radiation Protection” published as Title 246 of the Washington Administrative Code (WAC). These regulations refer to "persons engaged in activities under licenses issued by the Washington state department of health...” Since WTD does not have a license from the DoH, arguably these regulations do not apply. Following the same reasoning, the regulations of the U.S. Nuclear Regulatory Commission (NRC), the U.S. Department of Energy (DOE), and the U.S. Department of Defense (DoD) do not apply.

\subsection{Regulations that Do Apply to WTD}

Several sets of regulations apply to WTD.

\subsubsection{Transportation}

Under the U.S. DOT regulations (primarily 49 CFR 170-179), any contaminated material (e.g., rags and screenings, grit, and biosolids) above specified concentrations (usually taken as 0.002 microcuries per gram, $\mu \mathrm{Ci} / \mathrm{g}$ ) must be packaged, labeled, manifested, surveyed, and transported in specified ways. This could result in a serious problem for WTD, and under some circumstances, exceptions may be needed to DoT regulations in order to reduce elevated radiation levels in the plant low enough to continue normal operations.

\subsubsection{Environment}

Similarly, the regulations of the U.S. Environmental Protection Agency (EPA) would govern the ultimate fate of radioactively contaminated waste material such as rags and screenings, grit, or biosolids, as well as treated but still radioactively contaminated wastewater.

\subsubsection{Protection of Workers and the Public}

The Occupational Safety and Health Administration (OSHA) regulates workplace exposures for all sources of radiation that are not regulated by other federal or state agencies. OSHA has a 
single regulation entitled "Ionizing radiation” published as Title 29, Code of Federal Regulations (CFR) Section 1910.1096 (29 CFR 1910.1096). An agency such as WTD that does not have a license for the use of radiation or radioactive material is subject to this regulation. It should be noted that the OSHA regulation is essentially the regulation used by the U.S. Atomic Energy Commission at the time OSHA was created in 1974. Rather than referring to the "licensee," as the non-applicable regulations do, the OSHA regulations refer to the "employer."

The understanding of dose limits for WTD workers requires the concepts of restricted and unrestricted areas. In OSHA's parlance " $r$ restricted area means any area access to which is controlled by the employer for purposes of protection of individuals from exposure to radiation or radioactive materials. Unrestricted area means any area access to which is not controlled by the employer for purposes of protection of individuals from exposure to radiation or radioactive materials."

OSHA's dose limits for individuals age 18 and above are based on a calendar quarter, not on a year, as shown in Tables 1 and 2. OSHA's limits apply to exposures to radiation "sources in the employer's possession or control," so radioactive material in wastewater or its byproducts would appear to be "sources in WTD's possession."

Table 1. Dose limits for external irradiation of individuals 18 years old or older in restricted areas. One-tenth of these limits apply to individuals under age 18 years.

\begin{tabular}{|l|c|}
\hline & $\begin{array}{c}\text { Rems } \\
\text { per } \\
\text { calendar } \\
\text { quarter }\end{array}$ \\
\hline Irradiated portion of body & 1.25 \\
\hline Whole body; head and trunk; active blood-forming organs; lens of eyes; or gonads & 3 \\
\hline $\begin{array}{l}\text { Whole body; head and trunk; active blood-forming organs; lens of eyes; or gonads } \\
\text { (provided the worker's lifetime dose is less than 5 rems × (worker's age in years - 18) }\end{array}$ & 18.75 \\
\hline Hands and forearms; feet and ankles & 7.5 \\
\hline Skin of whole body & \\
\hline
\end{tabular}

Table 2. Limits on exposure to airborne radioactive material for individuals in restricted areas.

\begin{tabular}{|c|c|}
\hline Intake route & Limit \\
\hline $\begin{array}{l}\text { Inhalation (18 years old } \\
\text { and older) }\end{array}$ & $\begin{array}{l}\text { Cannot exceed the concentration specified in Table I of Appendix B to } \\
10 \text { CFR } 20^{\mathrm{a}} \text { for } 40 \text { hours in any 7-day period ( } 40 \text { derived air } \\
\text { concentration-hours [DAC-hours]) }\end{array}$ \\
\hline $\begin{array}{l}\text { Inhalation (under } 18 \\
\text { years of age) }\end{array}$ & $\begin{array}{l}\text { Cannot exceed concentration specified in Table II of Appendix B to } 10 \\
\text { CFR } 20 \text { averaged over no more than one week }\end{array}$ \\
\hline Ingestion & (not mentioned) \\
\hline Dermal absorption & (not mentioned) \\
\hline
\end{tabular}

${ }^{a} 10$ CFR 20 is the "U.S. NRC’s Standards for Protection Against Radiation.” 
OSHA's limits are old-fashioned by the standards used today by other regulatory agencies named above. Unlike more modern dose limits,

- the standards use the quantity dose equivalent, rather than effective dose equivalent

- there is a separate, additional limit for intakes of radionuclides

- there is no mention of dose to the public

- there is no mention of dose limits for declared pregnant women to protect the embryo/fetus

- reference is made to obsolete dosimetry technology (film badges)

- there is no requirement to keep doses as low as reasonably achievable (ALARA).

Under 29 CFR 1910.1096, WTD could declare areas of its facilities to be "restricted areas" for purposes of radiation protection. If WTD did so, there are implications for other parts of a radiation protection program. WTD would be obligated

- to perform surveys for radiation and radioactive materials $§ 1910.1096(d)(1)$

- $\quad$ to provide adequate radiation detection equipment $\$ 1910.1096(\mathrm{~d})(2)$

- to post areas with caution or warning signs §1910.1096(e)

- to provide immediate evacuation warning signals §1910.1096(f)

- to provide training for anyone entering the area $\$ 1910.1096(i)$

- to provide secure storage for radioactive material $\$ 1910.1096(\mathrm{j})$

- to dispose of radioactive waste to an authorized recipient or in a manner approved by the NRC or State of Washington $\$ 1910.1096(\mathrm{k})$

- to notify the Assistant Secretary of Labor of incidents within specified times $\S 1910.1096(1)$

- to provide reports of incidents within specified time frames $\S 1910.1096(\mathrm{~m})$

- to maintain records and provide certain reports to workers and former workers $\S 1910.1096(n)$.

It is not clear as of this writing what legal responsibility WTD has for protecting the public, since OSHA is silent on the matter and it is unclear whether WTD has obligations under EPA regulations when WTD may have little no control over public doses resulting from contaminated wastewater. The OSHA limits for persons under age 18 could logically be voluntarily applied, or at least stated as a goal, and this would be better than having no limits. Alternatively, WTD might state a goal of protecting the public to standards met by licensees of the State of Washington. However, it is unclear at present whether WTD has any legal duty in this regard.

\subsubsection{Disposal}

Emergency action on the part of Washington State officials may permit disposal of radioactively contaminated rags and screenings, grit, and biosolids within a reasonable time. Fortunately, Washington State has one of only three operating commercial low-level radioactive waste facilities in the US, located on the Hanford Reservation near Richland. It is regulated under WAC 246-249, "Radioactive waste -- Use of the commercial disposal site." 


\subsection{The “As Low As Reasonably Achievable” (ALARA) Philosophy}

A cornerstone of modern radiation protection philosophy is the notion of "as low as reasonably achievable" (ALARA). A commitment to ALARA means that WTD would, in addition to complying with laws and regulations, "make every reasonable effort to maintain radiation exposures, and releases of radioactive materials in effluents to unrestricted areas, as low as is reasonably achievable. [WTD] should make particular efforts to keep the radiation exposure of an embryo or fetus as low as is reasonably achievable during the entire gestation period as recommended by the National Council on Radiation Protection and Measurements. The term 'as low as is reasonably achievable' means making every reasonable effort to maintain exposures to radiation as far below the dose limits in these regulations as is practical, consistent with the purpose for which the licensed or registered activity is undertaken, taking into account the state of technology, the economics of improvements in relation to the state of technology, the economics of improvements in relation to benefits to the public health and safety, and other societal and socioeconomic considerations, and in relation to the utilization of nuclear energy, ionizing radiation, and radioactive materials in the public interest” (WAC 246-220-007).

\subsection{Current Radiation Protection Recommendations}

The National Council on Radiation Protection and Measurements (NCRP) was chartered by Congress in 1964 to advise the government on radiation protection matters. Its current recommendations (National Council on Radiation Protection and Measurements (NCRP) 1993) cover areas on which the OSHA regulation, 29 CFR 1910.1096, is silent. These recommendations are given in Table 3.

The NCRP's recommended public dose limit is 0.1 rem for routine exposure from all sources, but for accident conditions, it is 0.5 rem in a year, as in a radiological terrorism event.

Of particular note are the recommended limits for life-saving, 50 rems to the whole body and 500 rems to the skin. The existence of such recommendations for emergency situations should be recognized as indicating that, during off-normal situations, dose limits for normal, peacetime, non-emergency situations must be re-thought.

The NCRP recommendations also include application of the ALARA philosophy.

The NCRP recommendations do not have a legal standing at present, but may be adopted in the future for homeland security situations. 
Table 3. Summary of the 1993 Recommendations of the NCRP ${ }^{\mathrm{a}, \mathrm{b}}$

\begin{tabular}{|c|c|c|}
\hline & Category & Value \\
\hline \multirow[t]{7}{*}{ A. } & Occupational Exposures $^{\mathrm{a}}$ & \\
\hline & 1 Effective dose limits & \\
\hline & a) Annual & 5 rems \\
\hline & b) Cumulative & $1 \mathrm{rem} \times$ age \\
\hline & 2 Equivalent dose annual limits for tissues and organs & \\
\hline & a) Lens of eye & 15 rems \\
\hline & b) Skin, hands and feet & 50 rems \\
\hline \multirow[t]{3}{*}{ B. } & 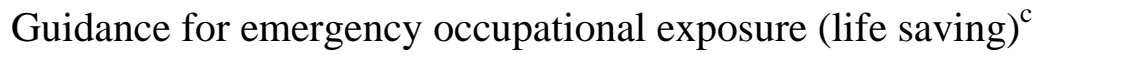 & \\
\hline & 1 Whole body & 50 rems \\
\hline & 2 Skin & 500 rems \\
\hline \multirow[t]{9}{*}{ C. } & Public exposures (annual) & \\
\hline & 1 Effective dose equivalent, continuous or frequent exposure ${ }^{c}$ & $0.1 \mathrm{rem}$ \\
\hline & 2 Effective dose limit, infrequent exposure ${ }^{c}$ & $0.5 \mathrm{rem}$ \\
\hline & 3 Equivalent dose limits for tissues and organs ${ }^{c}$ & \\
\hline & a) Lens of eye & 1.5 rems \\
\hline & b) Skin, hands and feet & 5 rems \\
\hline & 4 Remedial action for natural sources: & \\
\hline & a) Effective dose (excluding radon) & $>0.5$ rem \\
\hline & b) Exposure to radon decay products & $2 \mathrm{WLM}^{\mathrm{d}}$ \\
\hline \multirow[t]{5}{*}{ D. } & Education and training exposures (annual) ${ }^{\mathrm{C}}$ & \\
\hline & 1 Effective dose limit & $0.1 \mathrm{rem}$ \\
\hline & 2 Equivalent dose limit for tissues and organs & \\
\hline & a) Lens of eye & 1.5 rems \\
\hline & b) Skin, hands and feet & 5 rems \\
\hline \multirow[t]{2}{*}{ E. } & Embryo-fetus exposures $^{\mathrm{c}}$ (monthly, once the pregnancy is known) & \\
\hline & 1 Equivalent dose limit & 0.05 rems \\
\hline F. & Negligible individual dose (annual) ${ }^{\mathrm{C}}$ & 0.001 rems \\
\hline \multicolumn{3}{|c|}{${ }^{\mathrm{a}}$ Excluding medical exposures. } \\
\hline \multicolumn{3}{|c|}{ bee below for recommendations of wR and wT. } \\
\hline \multicolumn{3}{|c|}{$\begin{array}{l}\text { 'Sum of external and internal exposures but excluding doses from natural sources } \\
\text { d working level month, a unit of “dose” from airborne decay products of radon gas. }\end{array}$} \\
\hline
\end{tabular}

\subsection{Doing More than the Law Requires}

The WTD should strongly consider protecting its workers and the public to modern standards, such as those of WAC 246 sections 220 through 254. This standard, along with the NRC and DOE standards, specify an annual limit of 100 millirems ( 0.1 rem) for members of the public. Radiation workers are limited to 5 rems per year, with an ALARA condition as well.

WTD may be able to significantly lessen environmental impacts by treating contaminated wastewater and responsibly managing rags and screenings, grit, and biosolids. Such management would require cooperation and collaboration of state agencies for radioactive waste transportation and disposal. 


\subsection{Protection of Workers During and After an Emergency}

Choices for keeping worker doses below appropriate limits and for keeping those doses ALARA depend on the nature of the radiological situation and the amount and type of radioactivity involved. Volume 1 of PNNL-15263 (Strom 2005) presented a radiological risk analysis for the WPTP. Radiation protection options are broken down into the exposure pathways shown in Figure 2 of Vol. 1, that is, external irradiation, intakes of radioactive material by inhalation, intakes by ingestion, intakes through intact skin, wounds or injection, or irradiation by radioactive material on the skin (ontakes).

It must be emphasized that responding to a radiological contamination event falls under the radiation protection category of an intervention, rather than some planned, justified, and agreedon practice. As a result, some common-sense actions may be needed to limit radiation doses and intakes of radioactive material that would not be considered acceptable for a planned, justified, and agree-on use of radioactive material such as medical diagnosis and therapy in a clinical setting.

\subsection{Principles of Radiation Protection and Actions Based on Those Principles}

Several principles and actions (“commandments") of radiation protection are summarized in Table 4 (Strom 1996). Not all of these apply to all situations, so their use is detailed below in specific situations. For radiological terrorism resulting in radioactively contaminated wastewater, principles 9 and 10 are of little use.

The "zeroth" principle of radiation protection is to know the radiological situation through measurements of radiation levels and concentrations of radioactive materials. Whenever possible, radiation protection actions should be based on measurements, not speculation or guesses.

Table 4. Principles and Actions (“Commandments”) of Radiation Protection

\begin{tabular}{cll} 
No. & Principle & Commandment (familiar) \\
\hline 1. & Time & Hurry (but don't be hasty) \\
2. & Distance & Stay away from it or upwind of it \\
3. & Dispersal & Disperse it and dilute it \\
4. & Source Reduction & Make and use as little as possible \\
5. & Source Barrier & Keep it in \\
6. & Personal Barrier & Keep it out \\
7. & Decorporation (Internal \& Skin) & Get it out of you and off of you \\
8. & Effect Mitigation & Limit the damage \\
9. & Optimal Technology & Choose best technology \\
10. & Limitation of Other Exposures & Don’t compound risks (don’t smoke)
\end{tabular}




\subsection{Protection against External Irradiation}

By far the most likely route of exposure to WTD workers is by external irradiation. When radioactive material is dissolved or suspended in wastewater, or present in rags and screenings, grit, or biosolids, it can serve as a source of radiation. In addition, if the radioactive material somehow adheres to surfaces of pipes, pumps, valves, and other equipment in contact with these waste streams, it can also serve as a source of radiation. This means that radioactive materials like ${ }^{60} \mathrm{Co}$, which emits relatively penetrating gamma radiation, can irradiate WTD personnel if they are in proximity to any of those waste streams. There are numerous ways to reduce or limit radiation doses to workers. For WTD and the radionuclides listed in Volume 1, these include 1-5 and 8 from Table 4. These actions are broken down into those that individuals (workers) can take, and those that management can take.

\subsubsection{Actions Workers Can Take to Limit External Irradiation}

Actions that individuals can take include

- limiting exposure time by doing jobs in radiation fields quickly and efficiently, and then moving to an area with lower radiation levels (Table 4, \#1, time).

- staying away from a radiation source (Table $4, \# 2$, distance)

- ensuring that radiation-absorbing shielding is between the person and the radiation source (Table 4, \#5, source barrier). In the case of WTD, this generally means using existing water, pipe walls, concrete structures, and earth berms to absorb radiation by locating oneself in low radiation areas. However, shielding may involve moveable concrete, brick, steel, or lead barriers; bags of sand, salt, cement, or other non-radioactive material; water tanks; and earth brought in dump trucks or moved by earth-moving equipment.

\subsubsection{Actions Management Can Take to Limit External Irradiation}

Actions that management can take include

- invoking administrative (management) controls to ensure that workers take the actions listed in 3.2.1, above. This includes establishing restricted areas and radiation areas, and using postings to warn workers of radiation and contamination levels.

- dispersal of radioactive material by dilution in wastewater or bodies of water such as Puget Sound (Table 4, \#3, dispersal)

- source reduction by physical removal of contaminated material (rags and screenings, grit, biosolids)(Table 4, \#4, source reduction). This would mean removal of waste streams (dumpsters of rags and screenings, or of grit; trucks of biosolids) from the premises, or mechanical or chemical decontamination of portions of the plant (scouring the insides of pipes and tanks, altering $\mathrm{pH}$ or other chemical means to mobilize or precipitate contamination, filtration, etc.)

- erecting shielding, which may involve moveable concrete, brick, steel, or lead barriers; bags of sand, salt, cement, or other non-radioactive material; water tanks; and earth brought in dump trucks or moved by earth-moving equipment (Table 4 , \#5, source barrier). 
- dividing up "hot" jobs among many individuals so that no single person is exposed to too much radiation (Table 4, \#8, effect mitigation).

\subsection{Protection Against Intakes by Inhalation}

As explained in Volume 1, when radioactive material enters the body, it can be retained in the body for some time, depending on its chemical and physical form. Since, for obvious reasons, workers already minimize the inhalation of wastewater aerosols, vapors, and gases, and since there is enormous dilution in the WPTP, inhalation of radioactive materials dissolved or suspended in wastewater is not expected to be a significant route of intake ${ }^{1}$. However, for completeness, radiation protection measures that can be taken by individuals and by management to limit and minimize inhalation of radioactive material are described here.

\subsubsection{Actions Workers Can Take to Limit Inhalation of Radioactive Material}

Actions that individuals can take include

- limiting exposure time by quickly doing jobs where there is airborne radioactivity present, and then moving to an area with lower airborne radioactivity concentrations (Table 4, \#1, time)

- staying upwind from locations where there are significant airborne radioactivity levels, or far enough downwind that significant dilution has taken place (Table 4, \#2, distance)

- using ventilation (fans, blowers) to provide clean air or to disperse and dilute airborne radioactive materials (Table 4, \#3, dispersal). Many of the techniques used for confined space entry are applicable to limiting inhalation intakes

- minimizing the resuspension of radioactive contamination on surfaces (Table 4, \#4, source reduction). Resuspension is the process of taking dirt or some material on a surface and making it into an aerosol, that is, suspending it in the air like dust or mist. Resuspension can be minimized by various means, from moist cleaning to application of fixatives. Some cleaning methods, such as vacuuming, may aggravate resuspension unless done with special vacuuming equipment equipped with special filters designed specifically for the material to be vacuumed (e.g., HEPA filters for particulates, activated charcoal filters for organice materials with significant partial pressure).

- using personal protective equipment such as respiratory protection (negative-pressure filtered respirators, powered air-purifying respirators, or Scott air packs) (Table 4, \#6, personal barrier)

- if inhalation is suspected, nose-blowing, sneezing, coughing up and spitting out mucus from the respiratory tract can help get material out of the body (Table 4, \#7, decorporation).

\subsubsection{Actions Management Can Take to Limit Inhalation of Radioactive Material}

Actions that management can take include

\footnotetext{
${ }^{1}$ If radium contamination were persistent in a part of the plant, levels of airborne radon and progeny could grow to significant levels.
} 
- invoking administrative (management) controls to ensure that workers take the actions listed in 3.3.1, above, and providing workers with the training, equipment, and disposable gear that they need. This includes establishing restricted areas, contamination areas, airborne radioactivity areas, and using postings to warn workers of contamination and airborne radioactivity levels

- dispersing airborne radioactive material by dilution using existing or improvised ventilation systems (Table 4, \#3, dispersal)

- reducing airborne radioactivity levels by reducing the amount of radioactivity in the plant, using methods described in 3.2.2 (Table 4, \#4, source reduction)

- enhancing containment and confinement of radioactive materials within the plant to prevent or minimize aerosol generation and prevent or minimize evaporation of liquids (Table 4, \#5, source barrier). This may be particularly important for biosolids handling.

- dividing up "hot" jobs among many individuals so that no single person inhales too much airborne radioactive material (Table 4, \#8, effect mitigation).

\subsection{Protection Against Intakes Through Dermal Contact and by Ingestion}

For obvious reasons, workers already minimize the dermal contact with and ingestion of wastewater that may splash or spray or become an aerosols, vapors, or gas. Since there is enormous dilution in the WTD, ingestion of radioactive materials dissolved or suspended in wastewater is not expected to be a significant route of intake. However, for completeness, radiation protection measures that can be taken by individuals and by management to limit and minimize ingestion of radioactive material are described here.

In the context of minimizing ingestion of radioactive contamination, it is important to remember that radioactive contamination is just like dirt in the sense of "stuff being where you don't want it."

\subsubsection{Actions Workers Can Take to Limit Dermal Contact with, and Ingestion of, Radioactive Material}

Actions that individuals can take include

- preventing or minimizing contamination of anything that can be ingested or come in contact with the face (Table 4, \#4, source reduction). The "no hands above the collar before you wash your hands" rule that protects WTD workers from microbial infection will work to minimize ingestion of radioactive material. Thus, practical steps include the prohibition of

0 eating

o drinking

o smoking

o storage or preparation of food

0 chewing (gum, tobacco)

o application of cosmetics or lip balm, or

o contacting the face or head (biting nails, scratching, rubbing eyes, etc.) in areas where radioactive contamination may be on surfaces or in the air. 
- washing hands frequently. Good technique is necessary to washing one's hands without spreading contamination. Before people wash their hands, they should avoid door knobs, light switches, faucets, soap dispensers, etc. Clean tissues can be used to prevent direct contact. When direct contact with washroom fixtures is unavoidable, the fixtures should be washed to remove any contamination.

- minimizing the resuspension of radioactive contamination on surfaces (Table 4, \#4, source reduction). Resuspension is the process of taking dirt or some material on a surface and making it into an aerosol, that is, suspending it in the air like dust or mist. Resuspension can be minimized by various means, from moist cleaning to application of fixatives. Some cleaning methods, such as vacuuming, may aggravate resuspension unless done with special vacuuming equipment equipped with special filters designed specifically for the material to be vacuumed (e.g., HEPA filters for particulates, activated charcoal filters for organic solids or liquids with significant partial pressure).

- staying upwind from locations where there are significant airborne radioactivity levels, or far enough downwind that significant dilution has taken place (Table 4, \#2, distance)

- using ventilation (fans, blowers) to provide clean air or to disperse and dilute airborne radioactive materials (Table 4, \#3, dispersal).

- correctly using personal protective equipment such as gloves, boots, coveralls, hoods, and respirators (Table 4, \#6, personal barrier), including “donning” (dressing or putting on) and "doffing" (removing or undressing) without contaminating oneself. When doffing disposable gloves, spread of contamination can be minimized by turning them inside out while removing them and placing them directly into a labeled container (for example, a trash bag) where they will not be handled again.

- if skin contamination is suspected, decontamination (washing or other cleaning mechanisms) can help get material off of the body (Table 4, \#7, decorporation). Material taken onto the skin, an "ontake," irradiates the skin as long as it is present, so removing the radioactive material from the skin will stop the radiation exposure.

\subsubsection{Actions Management Can Take to Limit Dermal Contact with, and Ingestion of, Radioactive Material}

Actions that management can take include

- invoking administrative (management) controls to ensure that workers follow the actions listed in 3.4.1, above, and providing workers with the training, equipment, and disposable gear that they need. This includes establishing restricted areas, contamination areas, airborne radioactivity areas, and using postings to warn workers of contamination and airborne radioactivity levels

- dispersing airborne radioactive material by dilution using existing or improvised ventilation systems (Table 4, \#3, dispersal)

- reducing radioactive contamination levels by reducing the amount of radioactivity in the plant, using methods described in 3.2.2 and other decontamination methods (Table 4, \#4, source reduction)

- enhancing containment and confinement of radioactive materials within the plant to prevent or minimize

0 aerosol generation 
o evaporation of liquids

o spread of surface contamination

(Table 4, \#5, source barrier). This may be particularly important for biosolids handling.

- dividing up "hot" jobs among many individuals so that no single person comes into contact with too much radioactive contamination (Table 4, \#8, effect mitigation).

\subsection{Personnel Monitoring: External Dosimetry, Bioassay, and Air Monitoring}

OSHA regulations and good practice require that radiation workers (those frequenting a restricted area) participate in a personnel monitoring program. Such a program may include monitoring for dose received from external sources, monitoring for skin contamination, and monitoring for intakes of radioactive materials. A personnel monitoring program may also include workplace air sampling for personnel dosimetry purposes (Hickey et al. 1993).

\subsubsection{External Dosimetry}

Monitoring for dose received from external sources such as those listed in Volume 1 can be done using

- thermoluminescent dosimeters (TLDs)

- optically-stimulated luminescent dosimeters (OSLDs)

- electronic personnel dosimeters (EPDs) such as the Thermo Mk 2.3 (Figure 1) that WTD has purchased.

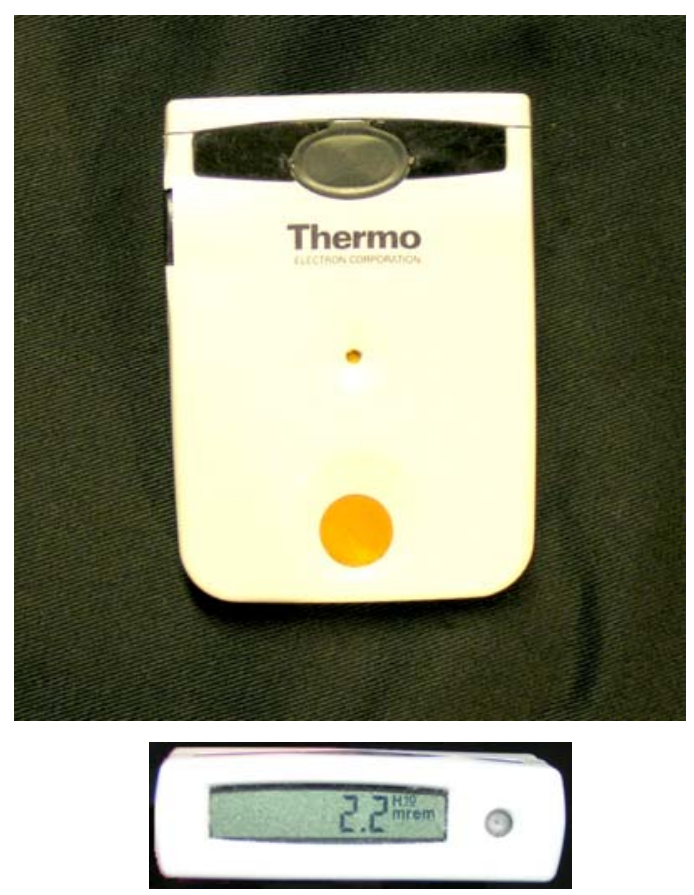

Figure 1. Thermo Mk. 2.3 electronic personnel dosimeter. 
Less precise, but still sensitive and far better than nothing, are pocket ionization chambers (PICs). PICs are charged with a piezoelectric charger, can be re-used, and are self-indicating dosimeters. Modern designs are quite rugged and insensitive to weather, humidity, vibration and impact.

Less precise, and only sensitive to emergency levels of dose are the newly developed passive

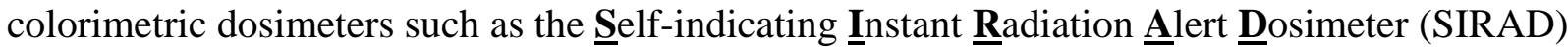
(http://www.jplabs.com/html/what_is_sirad.html), shown in Figure 2. The dosimeter is the size of a thick credit card and can be carried in a wallet. The dosimeters will be available to emergency responders for under \$5 each, and are good for one year.
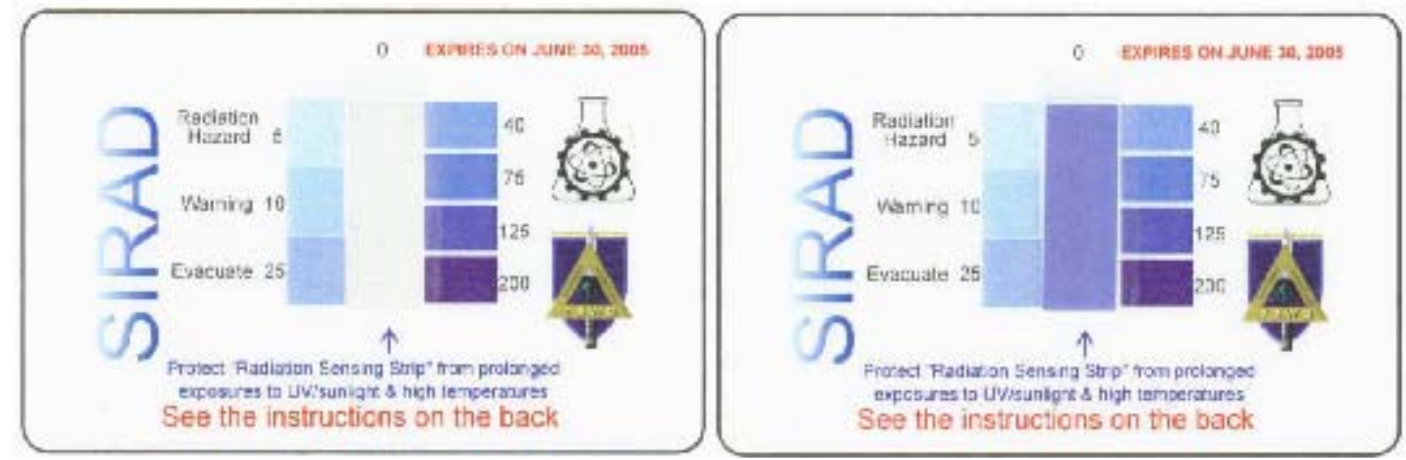

Figure 2. Photos of SIRAD dosimeters before (left) and after (right) irradiation with 100 rads of $\mathrm{x}$ rays. The color bars printed with dose numbers on each side of the sensing strip is referred to as the color reference chart. The dosimeter is the size of a thick credit card and can be carried in a wallet.

OSHA and other regulators require that radiation dosimetry records be maintained for radiation workers and stored under Privacy Act provisions.

Another approach to monitoring individuals for dose from external sources is to measure radiation levels (dose rates in millirems per hour or rems per hour), and record or estimate the time individuals spend in areas with those dose rates, and multiply the dose rate by the stay time to arrive at a dose. For example, a person spending 2 hours in a radiation field of 5 millirems per hour would receive a dose of 10 millirems.

\subsubsection{Bioassay}

In the context of exposure to radioactive materials that may be inhaled, ingested, absorbed through intact skin, or enter the body through wound or injection, "bioassay" means measuring radiation or radioactive material in a person or in bioassay samples such as exhaled breath, urine samples, or fecal samples. Direct measurement of radiation emitted from the body can be used to mesure intakes of gamma-emitters like the potential terrorist radionuclides ${ }^{60} \mathrm{Co},{ }^{137} \mathrm{Cs},{ }^{192} \mathrm{Ir}$, ${ }^{226} \mathrm{Ra}$, and ${ }^{241} \mathrm{Am}$ and common medical radionuclides ${ }^{67} \mathrm{Ga},{ }^{99 \mathrm{~m}} \mathrm{Tc},{ }^{99} \mathrm{Mo},{ }^{131} \mathrm{I}$, and ${ }^{201} \mathrm{Tl}$. Other radionuclides, such as the beta-emitting ${ }^{90} \mathrm{Sr}+{ }^{90} \mathrm{Y}$ and the alpha-emitting ${ }^{239} \mathrm{Pu}$ are best detected in urine and fecal samples. Such measurements can be used to estimate the intake in microcuries $(\mu \mathrm{Ci})$ and estimate a committed dose in rems. 
Similar record keeping requirements apply.

\subsubsection{Air Monitoring for Personnel Dosimetry}

Air samplers are available in a variety of forms. Some are suction pumps with special filters to intercept airborne radioactive dust or aerosols. Others are sorbents like activated charcoal. Some operate in real-time or nearly real-time, while others must pump for a while, have the filter removed and taken to a laboratory for counting, and analyzed. PNNL has led the effort to create a widely used document on workplace air sampling (Hickey et al. 1993) which details methods and procedures for performing air sampling.

Measurements of airborne radioactivity concentrations can be used along with worker stay-times and breathing rates (and respiratory protection factors, if used) to estimate intakes and doses.

\subsection{Radiological Surveys}

OSHA and good practice both require surveys of restricted and unrestricted areas for radiation levels, surface contamination levels, airborne radioactivity levels ( $\mu \mathrm{Ci}$ per milliliter), and radioactive material concentrations in wastewater and other waste streams. Such surveys are the basis for informing radiation protection decisions. Records must be maintained of such surveys.

\subsubsection{Radiation Levels}

Radiation survey instruments such as air ionization chambers or even Geiger counters (such as WTD's Inspector, Figure 3) can be used to measure radiation levels (dose rates in rems per hour or millirems per hour). 

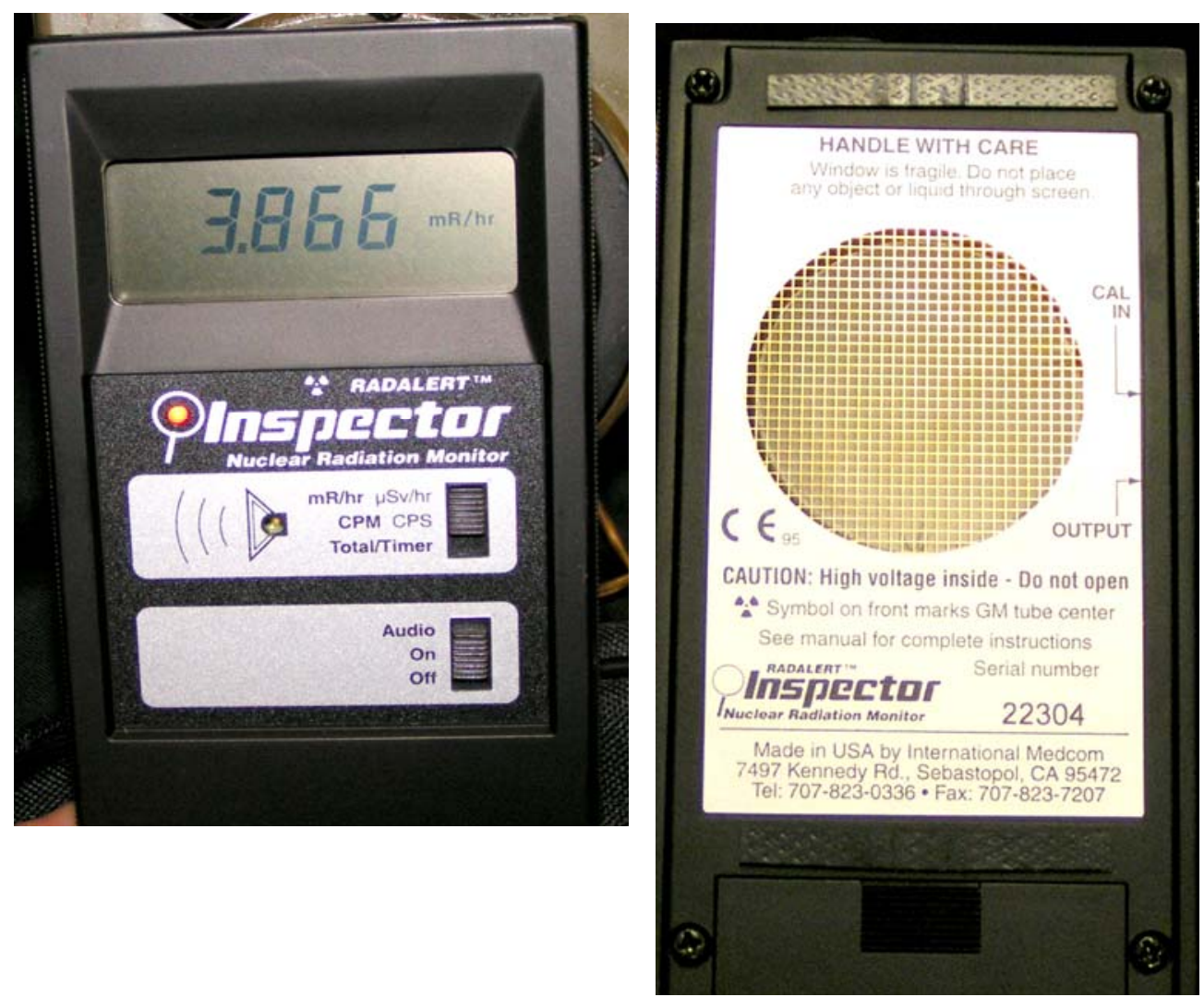

Figure 3. Front panel (left) and bottom (right) of Inspector. The unit has a "pancake” GeigerMuller probe built in (behind the gold screen) and can operate in count mode, count per minute mode, or dose-rate mode (in milliroentgens per hour, $\mathrm{mR} / \mathrm{hr}$ ).

\subsubsection{Surface Contamination Levels}

Levels of radioactive contamination on surfaces (in $\mu \mathrm{Ci}$ per 100 square centimeters) can be measured by wipe tests, in which the surface is wiped with a piece of filter paper and counted in a laboratory. Surface contamination can also be gauged using a pancake Geiger counter such as the Inspector operated in the counts per minute (cpm) mode or in the counts mode with the builtin timer. The Inspector can detect alpha-emitting radioactive material if the material is nearly in contact with the probe.

\subsubsection{Airborne Radioactivity Levels}

Measurements of airborne radioactivity levels (in $\mu \mathrm{Ci}$ per milliliter) must be made using specialized air sampling equipment.

\subsubsection{Radioactive Material Concentrations in Wastewater and Other Waste Streams}

Measurements of radioactive material concentrations in wastewater and other waste streams (in $\mu \mathrm{Ci}$ per gallon, per liter, per pound, per gram) are generally made by collecting a suitable sample 
and analyzing it using laboratory equipment (for low level samples) or using dose-rate instruments such as Geiger counters (for high level samples).

\subsection{Personal Protective Equipment}

Personal protective equipment includes gloves, boots, coveralls, hoods, and respiratory protective gear. For scenarios at WTD, the use of leaded gloves and leaded aprons does not make sense, since they are effective for only a very few radionuclides and not effective for many of the radionuclides a terrorist might use, including ${ }^{60} \mathrm{Co},{ }^{137} \mathrm{Cs},{ }^{192} \mathrm{Ir}$, and ${ }^{226} \mathrm{Ra}$. 


\subsection{Information Included in the Annex}

The WPTP Emergency Response Plan Annex will be different from the main body report because rather than responding to an event that takes place in the plant, such as a hazardous material spill or an explosion, the event will most likely take place outside of the plant and the radioactive material will be brought in with the wastewater. Where appropriate, the sections of the WPTP Emergency Response Plan will be referenced, rather than be totally repeated in the Annex

\subsection{Purpose and Objective of the Emergency Plan}

The purpose of the plan will be to provide guidance to protect workers that are processing wastewater that has been radiologically contaminated by malicious means or possibly by the inadvertent introduction of radioactive source that was accidentally lost and ended up in the storm or sewer system.

NOTE: Some levels of radioactive material may be in the wastewater from normal medical use. This material is not considered a hazard and is not an emergency.

\subsection{Detecting an Event}

It is assumed that prior to implementing the Annex, fixed radiation detection instrumentation will be deployed in the WPTP as described in Volume 2 of this report. Once installed and operational, this instrumentation will be used to detect radioactive material in the influent.

\subsection{Initial Response Notification and Communications during an Emergency}

There are two distinct types of notifications for a radiological event. The first is when it is known that wastewater has been contaminated and will be entering the WPTP and the second is if the contaminated wastewater enters the plant and is detected after entering the plant. Protocols for notifications of both situations must be in place. The first situation may require negotiations with local first responder organizations (fire or police) or appropriate emergency response organizations to make sure the necessary notifications are made to the WPTP managers so that they can be prepared for the material entering the plant.

The second situation, where material enters the plant and detected through fixed or portable instrumentation will require notifications more similar to that of a leak or spill in the plant. It should be noted that medical radioactive wastes are routinely released into the sewer system and are not considered emergencies nor are they hazardous to workers.

The notification procedure for outside of WPTP is the same as that provided on pages 2-4 though 2-5 of the Emergency Response Plan.

Figure 4 indicates the process of notifications for events detected both before the wastewater reaches WPTP and if it is detected first at WPTP. 


\section{Notification and Initial Response}

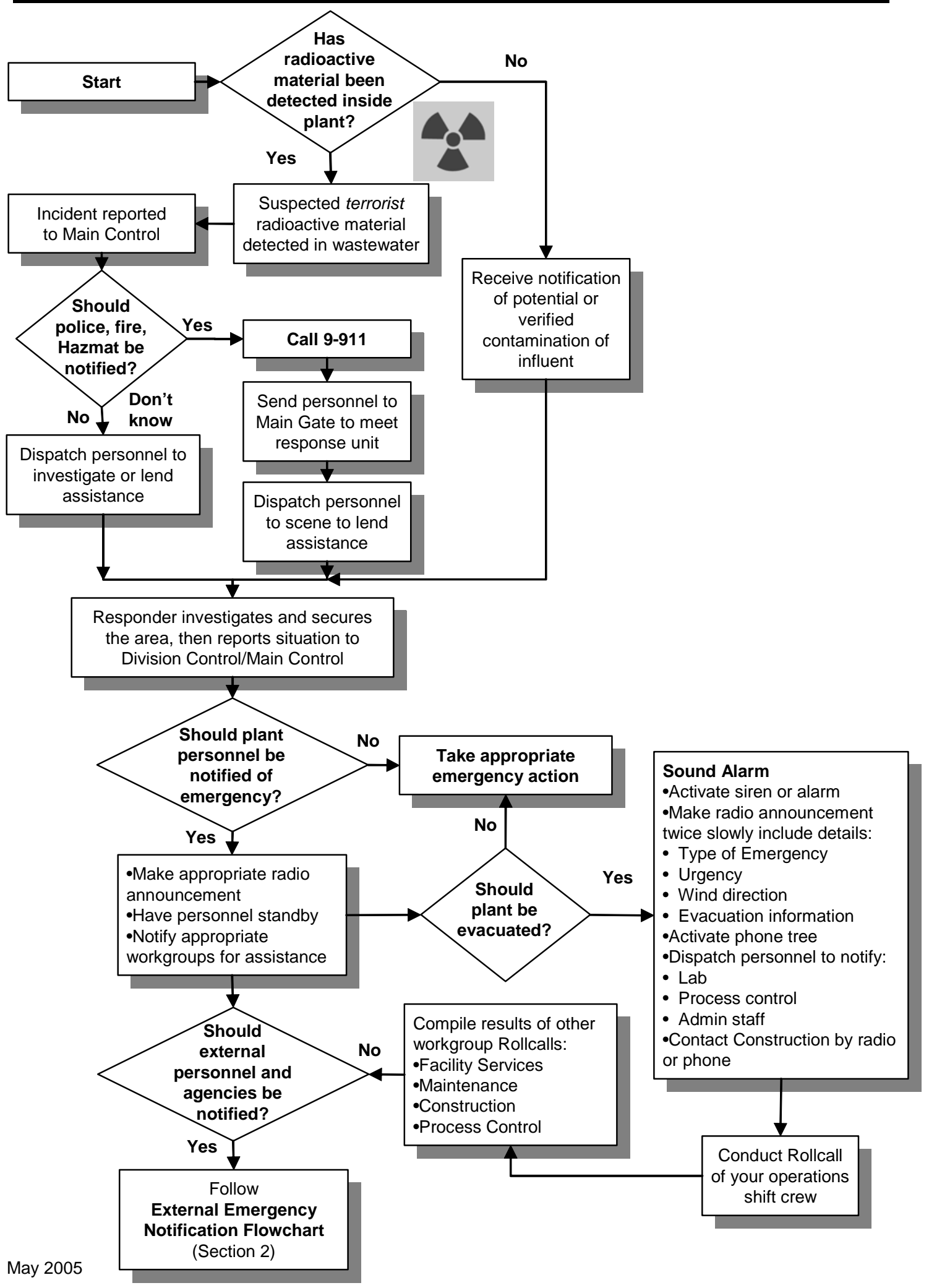

Figure 4. Notification and Initial Response in case of a Radiological Event. 
Emergency Communications during a radiological event can follow the procedures outlined in the WPTP Emergency Response Plan, pages 1-6 to 1-7.

\subsection{Roles and Responsibilities}

The Incident Command System will be in place as described in Section 3 of the WPTP Emergency Response Plan.

If radioactive material is detected in the wastewater and was not previously known, there will likely be more impact to for the onsite Incident Commander because, in addition to dealing with the radioactive material in the process systems, there will be investigations to determine how the material got there.

At the very minimum, the Washington $\mathrm{DOH}$ would be requested to sample the material as part of investigating how the material entered the system.

\subsection{Protecting Workers and the Public}

The public will be protected from contaminated wastewater prior to its entry into the plant by the structure of wastewater pipes and the normal controls excluding the public from pump and regulator stations. Also, the public will be protected from contaminated wastewater while it is in the WPTP by the same features. After the contaminated wastewater is released from the plant, the public will be protected by the same mechanisms that protect from the release of untreated sewage, that is dilution and release at a remote location. The public will be protected from other contaminated waste streams, such as rags or biosolids, by their proper transportation and disposal.

\subsection{Cleanup and Decontamination}

The Annex will generally address how to minimize the spread of by use of basic radiation protection principles.

The Annex will not specifically address cleanup and decontamination of the systems at the WPTP. However, once the contamination material has been processed through the facility and no more contaminated influent is entering the system, it is likely that the systems will be contaminated. It will be necessary to have the DOH or a private consultant provide assistance in determining the level of contamination and determine whether processing uncontaminated influent will result in producing unacceptably contaminated effluents and biosolids. 


\subsection{Suggested Revisions to WPTP Emergency Plan}

The following suggested revisions will incorporate considerations of radiological events into the WPTP Emergency Plan

Preface; page vii: Under the heading "What This Manual Covers," add a bullet that addresses an Appendix to the Emergency Plan that addresses procedures for responding to a radiological event. Under the heading "Safety Training Program", add a topic called Responding to a Radiological Event.

Preface; page x: Under the heading "Regulations Met by this Plan,” add 29 CFR 1910.1096; ionizing radiation (OSHA).

Section 3, page 3-3 under the heading "First Responder at the Awareness Level," add note that response to radiological emergencies is in the Annex.

Section 5, add note that response to radiological emergencies is in the Annex

Section 7, page 7-2 under heading "Hazmat Cleanup and Decontamination," add note that influent containing radioactive material that may have been spilled or is outside the normal wastewater process should only be handled by individuals trained to deal with radioactivity. 


\subsection{Conclusions and Recommendations}

Review of the June 2004 WPTP Emergency Response Plan and a tour of the WPTP facility was conducted by PNNL staff to determine the best approach to respond to an event resulting in wastewater entering the plant that contains radioactive material. The current plan adequately addresses most emergency response actions such as notification, communication, responsibilities and protective response. Therefore, it was determined that the Annex needed only to provide those details that differ from response from a hazardous material spill at the facility.

In order to effectively implement the proposed Emergency Response Plan Annex, PNNL has two recommendations to ensure successful implementation of the Annex.

\subsection{Training}

The training of staff that will be responding to the incident (especially WTD operations and maintenance personnel) will be necessary to be able to safely respond to radioactive material in the wastewater. At a minimum, the following groups of individuals should be trained for a radiological event at the WTPT: plant manager, on-shift operations supervisors, operations and maintenance personnel, and safety officers.

The training should cover at a minimum: 1) basic understanding of radiation, radioactive materials, and their potential effects on health, 2) regulations for protecting workers, 3) the ALARA philosophy, 4) basic principles of radiation protection, 5) application of those principles at WPTP, 6) use of personal protective equipment, and 7) detecting and responding to a radiological emergency at WPTP.

\subsection{Health Physics Consulting Agreement}

In order to adequately protect WPTP staff and perhaps protect systems and equipment during extensive processing of contaminated wastewater, it is highly recommended that a consulting agreement be placed with a trained health physicist as part of implementation of this plan. This individual would be responsible for planning and conducting radiological surveys, perform monitoring of staff, keep records of exposure, recommend PPE and assist in determining what systems are contaminated after the influent has been processed and make recommendations for decontamination. Relying on the health physics staff at the DOH may not be feasible because if there is an RDD, the staff may have their hands full with other duties. 


\subsection{References}

Hickey EE, GA Stoetzel, DJ Strom, GR Cicotte, CM Wiblin, and SA McGuire. 1993. Air

Sampling in the Workplace. Final Report. NUREG-1400; PNL-7814, U.S. Nuclear Regulatory Commission, Washington, DC.

National Council on Radiation Protection and Measurements (NCRP). 1993. Limitation of Exposure to Ionizing Radiation. Report No. 116, NCRP Publications, Bethesda, Maryland.

National Council on Radiation Protection and Measurements (NCRP). 2001. Management of Terrorist Events Involving Radioactive Material. PNNL-13945. NCRP Report No. 138, NCRP Publications, Bethesda, Maryland.

Strom DJ. 1996. "Ten Principles and Ten Commandments of Radiation Protection. PNWD-SA4290." Health Physics 70(3):388-393.

Strom, DJ. 2005. Volume 1: Task 2.1 Report Radiological Risk Assessment for King County Wastewater Treatment Division. PNNL 15163-Vol 3, Pacific Northwest National Laboratory, Richland, Washington. 